\title{
Study of dental specialists' awareness of additive manufacturing in dental practice.
}

\author{
Dobromira Shopova $^{1}$, Anna Mihaylova ${ }^{2}$, Penka Petleshkova ${ }^{3 *}$, Desislava Bakova ${ }^{4}$ \\ ${ }^{1}$ Department of Prosthetic Dentistry, Medical University of Plovdiv, Bulgaria \\ ${ }^{2}$ Medical College, Medical University of Plovdiv, Bulgaria \\ ${ }^{3}$ Department of Obstetrics and Gynecology, Medical University of Plovdiv, Bulgaria \\ ${ }^{4}$ Department of Health Care Management, Medical University of Plovdiv, Bulgaria
}

\begin{abstract}
Introduction: Additive manufacturing is an innovative technology, a revolution in medical industry. Constructions made of various chemical materials; resins, polymers, metals etc. can be manufactured by 3D printing in dental practice.

Purpose: A study of the awareness of dental specialists on additive manufacturing (or 3D printing) and its application in dental practice.

Conclusion: The majority of participants in the study are informed of the application of additive manufacturing in dental practice. Age is a significant factor for awareness-participants aged up to 40 years old are significantly more informed of the potential of 3D printing in comparison with their older colleagues $\left(\mathrm{p}=\mathbf{0 . 0 1}, \chi^{2}=110.156\right)$.
\end{abstract}

Keywords: Additive manufacturing, 3D printing, Dentistry.

Accepted on March 25, 2019

\section{Introduction}

Printing technologies of spatial objects in dental medicine are created with the aim of rationalizing the clinical and laboratory stages in manufacturing specific constructions-models, prototypes of temporary constructions-which are fabricated by a direct method in the patient's mouth (mockup), temporary crowns and dental bridges, guides in implantology, orthodontic appliances, maxillo-facial dentures [1-3]. Execution of all phases from the preparation (work model) till the final restoration is possible [4,5]. Multi-layered constructions give the opportunity to create internal cavities similar to natural fungi or bones. With the traditional techniques of milling and monolithing restorations this is not possible [6]. The applied materials in biological printing are subject to a constant study and control $[7,8]$.

Additive manufacturing exerts a significant influence on patients' dental health and has the potential for plenty of innovations. In order to realize its potential, dental specialists need to be informed and trained properly. Furthermore, the necessary measures for training and education need to be consistent with the specific needs of the population (consumers, patients) that also need to be informed adequately on the $3 \mathrm{D}$ printing existing opportunities.

\section{Purpose}

To study the degree of awareness of dental specialists on additive manufacturing (3D printing) and its application in dental practice.

\section{Materials and Methods}

146 dental specialists at an age from 21 to 68 years (mean $37.36 \pm 0.79), 45.9 \%$ of whom are women, participated in an anonymous survey. A questionnaire aiming to evaluate the degree of awareness on the application of $3 \mathrm{D}$ printer methods and materials was developed for the purposes of the survey (Figure 1). The questionnaire was distributed online among doctors of dental medicine and dental technicians. The respondents' answers were filled in a table which facilitated significantly the survey. The data was processed using the specialized statistical software SPSS 20. Descriptive statistics were presented as frequency, mean \pm standard deviation. Chi square test was used to evaluate the significance of difference. A $p$ value of $<0.05$ was accepted as statistically significant. 


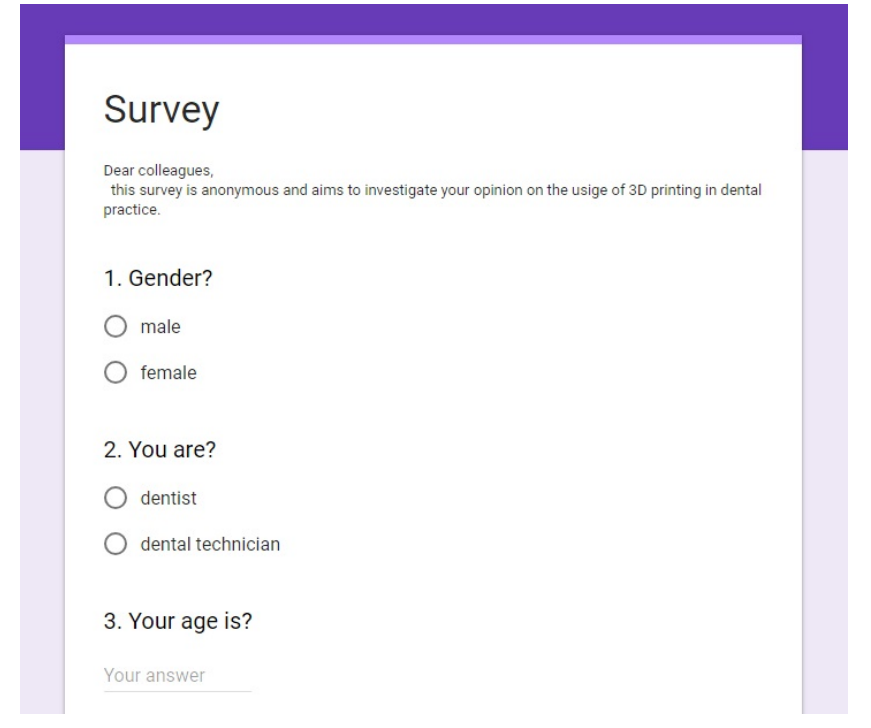

Figure 1. E-form of the questionnaire for dental specialists.

\section{Results}

Doctors of dental medicine comprise $51.4 \%$ of all participants in the survey (Figure 2).

Regarding our survey, it was important to establish the degree of participants' awareness in the questionnaire. The answers' distribution of the question: "Do you feel informed about the application of 3D printers for the purposes of dental medicine?" is presented in Figure 3. The majority of respondents $(68.5 \%)$ admitted they were partially informed about the topic. $26 \%$ were fully informed of the innovation, the predominant part being dental technicians $(p<0.05)$. Despite the fact that additive manufacturing is a comparatively new technology, only $5.5 \%$ of the surveyed dental specialists are not informed about its application.

We found a statistically significant difference between dentists and dental technicians regarding their awareness of the application of additive manufacturing $\left(p>0.05, \chi^{2}=5.526\right)$. Age exerts a significant influence on awareness. Younger participants in the survey are significantly more informed of the possibilities of $3 \mathrm{D}$ printing in comparison to their older colleagues $\left(p=0.01, \chi^{2}=110.156\right)$. We established statistically significant differences with respect to gender-male respondents are the better informed group. $\left(\mathrm{p}=0.042, \chi^{2}=6.333\right)$.

We added specifically which objects we have in mind to the question "Do you approve of 3D printing of objects for assistance (models, surgical guides)?" Figure 4 shows the distribution of answers almost $90 \%$ of respondents approve of printing of objects for assistance; models, surgical guides etc.

Figure 5 combines two questions about the approval of objects with prolonged and permanent contact. Having in mind its specificities, some of the 3D printed objects have extended or have prolonged contact to vital tissue. Despite the lack of ethical dilemmas, these aspects could cause certain reservations on the side of the dental specialists on their use in dental practice. Therefore, we asked the participants whether they approve of these conditions. We found that $82.2 \%$ of respondents definitely approve of the application of removable prosthetic appliances, orthodontic apparatuses, temporary crowns which are part of 3D printed appliances with a prolonged contact to vital tissues. About $17.1 \%$ of respondents cannot decide but none of them expressed disapproval. Once again the definitely positive answers among younger specialists predominate $\left(p=0.018, \chi^{2}=94.750\right)$. We found no statistically significant difference with regard to sex and profession.

The technological development of dental medicine is related to the constant search for possibilities for improving the quality of life of patients with dental problems. Recently, implantology has developed rapidly and it offers solutions which improve the patients' status considerably. Its application is related to the use of printed objects which, due to their specificities, are in prolonged contact with vital tissue. We found that more than half of the participants $(71.9 \%)$ responded positively to the question". Do you approve of 3D printing of objects in dental medicine which are in prolonged contact with vital tissues (implants, bridge constructions)?" dental specialists of up to 40 years old being the predominant group $(71.9 \%)$. We found a slight difference, but not a statistically significant one, in the distribution of the participants according to sex ( $>0.05$, $\chi^{2}=5.343$ ). The profession does not exert a significant influence on approval. Lack of familiarization with the methods or lack of competences for its application in dental practice could be potential causes for disapproval or inability to decide.
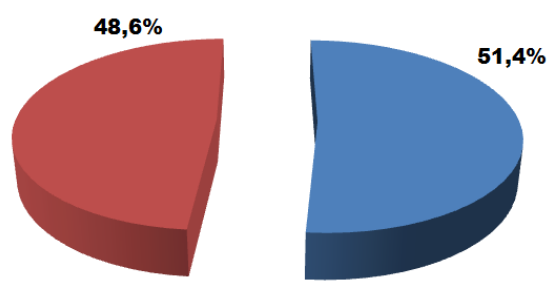

nentists

ndental technicians

Figure 2. Distribution of respondents according to profession.

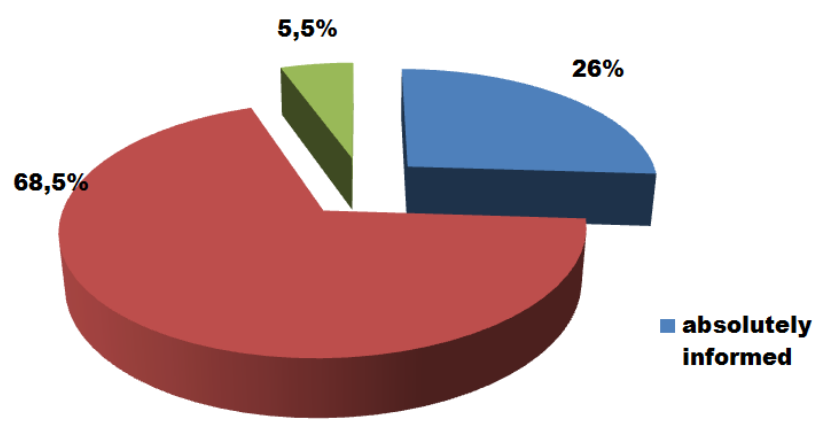

Figure 3. Distribution of degree of awareness. 


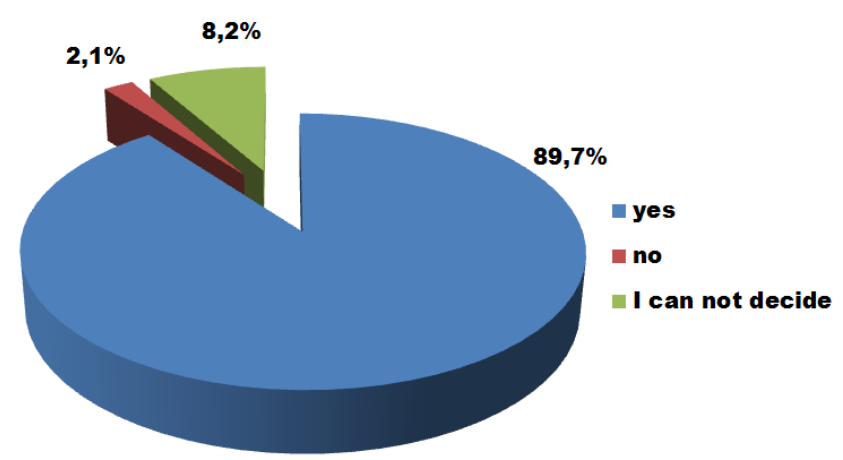

Figure 4. Approval of printing of objects for assistance.

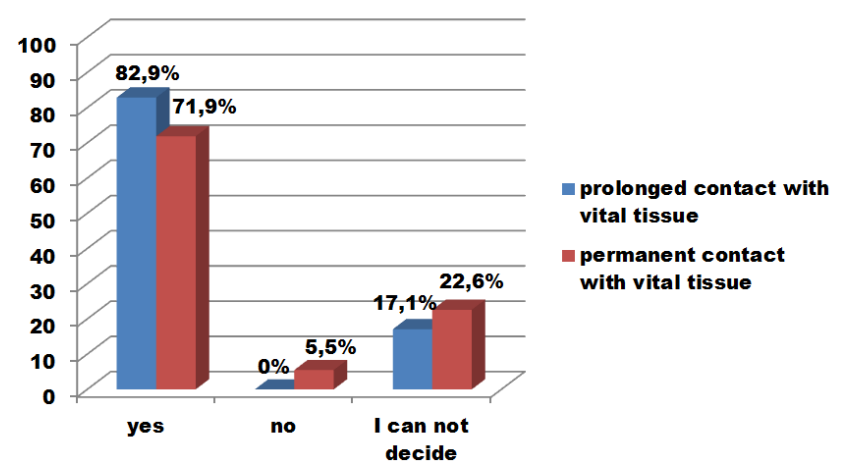

Figure 5. Approval of the application of object printing.

\section{Conclusion}

A comprehensive study could not be performed due to the insufficient number of studies on the dental specialists' awareness of 3D printing and the possibilities for its application in dental practice. A variety of methods described by the general term 3D printing exist. Insufficient studies of long-term usage, the reaction of the body and the behavior of the printed object itself in a vital environment requires their careful application $[7,8]$.

Dental medicine is one of the most rapidly developing medical spheres in a technological aspect. This is evidenced by the fact that it is in dental medicine that $3 \mathrm{D}$ printers have the most extensive application. Bearing in mind the expected benefits from the application of bioprinters (the products of additive manufacturing), numerous positive effects: improvement in people's quality of life, the manufacturing of replacement tissues specific for each patient, which provide better chances for recovery and achieving beneficial results following extensive reconstructive interventions, stand out. In order to achieve all that has been mentioned, it is necessary that dental specialists use all possibilities for improving their knowledge, skills, and competences for the efficient application of methods for improving the results from dental treatment and patients' quality of life.

\section{References}

1. Berman B. 3-D printing: The new industrial revolution. Business horizons 2012; 55:155-162.

2. Dawood A, Marti Marti B, Sauret-Jackson V, Darwood A. 3D printing in dentistry. Br Dent J 2015; 219:521-529.

3. Sun J, Zhang FQ. The application of rapid prototyping in prosthodontics. J Prosthodont 2012, 21:641-644.

4. Van Noort R. The future of dental devices is digital. Dent Mater 2012; 28:3-12.

5. Dikova T, Dzhendov D, Simov M, Katreva-Bozukova I, Angelova S, Pavlova D, Abadzhiev M, Tonchev $\mathrm{T}$. Modern trends in the development of the technologies for production of dental constructions. J of IMAB 2015; 2:974-981.

6. Rengier F, Mehndiratta A, von Tengg-Kobligk H, Zechmann CM, Unterhinninghofen R, Kauczor HU, Giesel FL. 3D printing based on imaging data: review of medical applications. Int $\mathrm{J}$ Comput Assist Radiol Surg 2010; 5:335-341.

7. Food and Drug Administration (FDA). Use of International Standard ISO 10993-1, Biological Evaluation of Medical Devices-Part 1: Evaluation and Testing within a Risk Management Process. 2016.

8. Chia $\mathrm{HN}, \mathrm{Wu} \mathrm{BM}$. Recent advances in $3 \mathrm{D}$ printing of biomaterials. J Biol Eng 2015; 9:4.

\section{*Correspondence to}

Penka Petleshkova

Department of Obstetrics and Gynecology

Medical University of Plovdiv

Bulgaria 